\title{
FEELING AND EMOTION
}

\author{
BY ARTHUR I. GATES \\ Teachers College, Columbia University \\ The Emotions-Theoretical
}

Link (13) is convinced that "the classical concepts of emotions and instincts are a hindrance rather than a help to future studies." By regarding the emotion as a mental state and the instinct as the bodily change which characterizes the emotion, "it is made absolutely impossible to establish any causal identity, or even a schematic identity between the two." For example, experiments with animals are quite futile because it is impossible to secure data on the psychic phenomena. The classifications of emotions given by McDougall and others are said to be entirely arbitrary and misleading. If emotions are, as McDougall believes, fixed and independent in character, it is impossible to account for their fusion into "sentiments" which are more powerful than the fundamental forces themselves; "only the most fanciful and uncritical imagination can follow the process by which it is done."

Kantor (II), none the less destructive, is more constructive in his two articles $\mathrm{He}$ submits that the emotion is not a positive response to a stimulus, but rather a failure of a stimulus-response coördination to operate Emotions are essentially "no response" activities The individual left without a directed mode of adjustment is thrown back upon primary responses, namely, the organic reflexes. "It is these replacement" reflexes which give emotional conduct the appearance of positive adjustment."

Several consequences must follow from such a negative character of emotions as Kantor describes. I. Emotional activity can be of no general and necessary utility to the organism; in fact, emotional conduct must be always truncated and ineffectual action, "disrupting chaos," momentary paralysis. 2. Emotional conduct must not be interpreted as an hereditary form of behavior, since it is due to the breakdown of acquired stimulus-response systems or to the absence of adaptive reactions. 3. Because emotions are "no response" actions, they cannot readily be clas-

${ }^{1}$ Italics mine. 
sified. Each must be studied as it occurs, in connection with its particular stimulus-response conditions. Most misleading has been the custom of connecting emotions with "those teleological entities called instincts." 4. It follows from the disruptive character of emotional behavior that emotions are seldom, if ever, observed in animals and young children, since such organisms have not reached the stage of acquiring sufficient response systems to become disrupted. Kantor urges the discard of the search for biological utility for a direct study of emotions as responses to "disrupting conditions of the environment."

Shand (22) has restated objections to McDougall's theory of the association of specific primary instincts with specific emotions. The emotion is a general activity, including an impulse, aroused when an instinctive impulse is not leading successfully toward its consummation.

Differing from all these hypotheses, and in most respects the very antitheses of Kantor's, are those appearing in Woodworth's recent Psychology (26). While the emotion is, introspectively, a "stirred-up state of mind," suggesting a breakdown of the organism's integrations, as a matter of fact, the "emotion represents internal preparation for some type of over action." It is pointed out that although sustaining evidence of utility is lacking in the case of many emotional states, there is no noteworthy contradictory evidence. For example, the fact that certain emotions, under civilized conditions, may be of no utility, does not discredit the theory since it is based on the assumption of adaptation to primitive environment, and not perfect adaptation at that.

Woodworth makes good use of the James-Lange theory without accepting it wholly. The trouble, in his opinion, has been a confusion of emotions with impulses, the latter being really the criteria by which emotions have been differentiated in speech. Fear and anger, as organic states, are much alike, but as impulses quite unlike. Typically, the impulse generates the emotion, but the emotion is never the same as the impulse. Temporarily the order of events is: Stimulus, say, a bear; Response, (a) seeing the bear; (b) recognizing a dangerous situation; (c) adjustment toward escape (i.e., impulse); (d) internal preparatory reactions, glands, visceral mechanisms, etc.; (e) conscious stirred-up state consisting of blended sensations of all these preparatory reactions (i.e., emotions); $(f)$ definite escape reaction.

Emotions are "native states of mind; or, as modes of behavior, they are like instincts in being native behavior." Like McDougall 
he posits certain primary emotions, such as anger, fear, lust, "the comfortable state appropriate to digestion," grief, mirth, disgust, curiosity, the tender emotion and "probably a few others." The really distinct primary emotions are much fewer than the instincts, but "several of the primary emotions are attached to specific instincts." While this sounds like McDougall, the theories are essentially different; the presence of a primary emotion is not, for Woodworth, the criterion of the primary instinct. The important relationship is merely that in some cases the emotion represents bodily readiness for instinctive action. Woodworth's theory is thus an adaptation of the hypotheses of James, McDougall and Cannon, with certain features found in none of them.

McDougall's analysis of belief (16) leads him to include it with confidence, hope, anxiety, etc., which are treated in the Social Psychology as "derived emotions." All of these are members of or named points in a continuous scale of emotional experiences which may accompany and qualify the operation of any strong desire. Belief is very similar to confidence.

Larguier des Bancels (I2) finds the emotional chill experienced by the observer of art, music, etc., to be a residual of primitive fear whose stimulus was the mysterious. The chill may appear in admiration, since the latter is a compound of curiosity, humility, and fear.

Janet (9) has submitted as a general explanation of phobias, the "fear of action." The phobia is an alibi or defense mechanism which enables the subject to avoid some unpleasant work or activity. Kaiser (ro) has discovered a new generalization which is alleged to include all springs of action. He finds that a "craving for thrill" is the fundamental instinct, and that all varieties of activity are its results. The interesting implication of this paper is the convenience with which "sex" might be substituted for "thrill," or how, in Freud's writings, the reverse might be done without interfering with the underlying logic of either system.

Buscaino (4) describes a number of clinical cases portraying disturbed emotionality correlated with defects of the mid-brain, particularly the thalamus. He adopts a theory, essentially the James-Lange, which, he finds as did Titchener earlier, has been repeatedly framed from the time of Aristotle.

The new and admirable text on the form and function of the central nervous system, by Tilney and Riley (23), includes frequent generalizations concerning the localization and dynamics of 
emotions and feelings. The belief that the frontal lobe dominates all behavioral reactions is reminiscent of Wundt. The rich connections of the frontal lobes with the thalamus provides for a great expansion of feeling tone "which plays such a compelling part in the motives of all voluntary activity." All of the superstructures posited by these writers are clearly patterned after the theories of McDougall. For example, "the primitive emotions enter into secondary and tertiary combinations, and thus determine the more complex emotions and sentiments. Yet however complex they may become, these psychic combinations of the cerebral cortex are fundamentally dependent upon the thalamus for their primitive source of affective energy." The reader who seeks the evidence of this dependence, or how it comes about, will be disappointed.

\section{The Emotions-Experimental Studies}

A study of emotional expressions by means of photographs reported by Ruckmich (20) showed, as did similar experiments by Langfeld, that the mood of the subject colors the interpretation. It was found that the lower half of the face provides more important clues than the upper, and that the mouth and eyes provide specially important signs.

Russell's selections (2I) from the poetic writings of Browning provide interesting descriptions of emotional consciousness and expressions.

Ferrari (8) and Gualino (9) have described the behavior of several soldier deserters condemned to be shot. It was found that evidence of disintegration appeared earliest in the postural reflexes, mental control usually being maintained until the last.

The possibilities of detecting deception by the use of objective tests are optimistically described by Marston (15). While the galvanometric, association reaction-time and the Benussi breathing tests were found wanting, the systolic blood pressure records were reported to have given "100 per cent. accuracy of judgment under very different conditions." Burtt $(2,3)$ has improved the Benussi inspiration-respiration ratio procedure for determining the lying consciousness and finds it a useful supplement to blood pressure methods. The latter he finds misleading in ro per cent. of the cases.

An introspective and questionnaire study of the development of admiration by Moore (I7) shows pronounced age differences, 
characterized by a decline in admiration of relatives and religious characters, and an increased admiration of brave and powerful public characters. A great decrease in the relative numbers of fears and fear dreams between ages four and nine (from 80 to 12 per cent.) appeared in an investigation by Boyd ( $\mathbf{r}$. This writer believes that both specific and general fears are inherited, the criterion being the unlikelihood of opportunity for acquiring them. The instinctive fears have as stimuli, eyes, teeth, snakes, great wild animals, wind and sea and death.

Pressey (I9) has offered a second revision of a series of four group tests of emotional traits. Basing his statement on the study of a hundred college students, the author says that "such examinations will be more accurate than Army Scale Alpha in prognosticating unsatisfactory work in college."

\section{Feelings-Theoretical}

Along with his criticisms of the classical concepts of the emotions, Link (13) finds equally great defects in the treatment of the affective processes. These, he finds, are not emotions, nor are they guides or results of emotions. The feelings are, in fact, the more fundamental, both genetically and actually, since they appear merely as symptoms of "getting along well" and "getting along badly." Since feelings, however, imply a normal course or "possibly a purpose," we must look still deeper for the fundamentally dynamic factors of behavior.

Kantor (II) believes that his naturalistic theory of emotions (the emotion being a collapse of situation-response adjustment) provides the setting for a precise distinction between these phenomena and feelings. The presence of an organized response system in the act is the criterion of feeling. Furthermore, feelings may be conceived as having potency to condition other activities, "in the sense that while they are operating they will affect any activity the person is performing," whereas the emotion, being merely the replacement of organized responses by a chaos of organic reflexes, has no such dynamic influence.

Woodworth (26) adopts the concept of simple feelings, i.e., pleasantness and unpleasantness together with a neutral state of indifference. The simple feelings differ from sensations in that (I) they cannot be introspectively observed as sensations may; (2) they cannot be localized as sensations may; and (3) they have no definite sense organs. They are not considered to be associated 
with definite organic activities, because of the overlapping of states of pleasantness and unpleasantness; nor with differences in the ease of brain action, since the facts of practice would contradict such an hypothesis. The fact that feelings are associated with impulses is at the core of the whole problem. Pleasantness goes with a neural adjustment directed toward keeping ... while unpleasantness goes with an adjustment toward riddance. The nearest approach to a statement of cause is this: "Bitter is unpleasant because we are so organized, by native constitution, as to make the riddance adjustment on receiving this particular stimulus. In plain language, we seek to be rid of it, and that is the same as saying it is unpleasant. Sweet is pleasant for a similar reason. In indifference there is no tendency either to keep or to be rid of it."

There are, however, two kinds of feelings:( $I$ ) those typified by sweet and bitter which are immediately and invariably aroused and (2) those which may be called secondary because they depend on "pre-aroused desires," i.e., eating, fighting, catching a train. "Just arouse any desire, and then you can give pleasure by gratifying it, displeasure by thwarting it." There are, also, native likes and dislikes, such as those for mathematics, music, colors, which may be contrasted with acquired likes and dislikes, such as those for cheese, tobacco or color combinations. Woodworth contends in opposition to McDougall that the likes and dislikes for mathematics, odors, machinery, etc., are not necessarily dependent upon instincts but are primary.

Duprat (6) suggests as a basis for the practical classification of men, the expansive and depressive types. Starting from some of the data on feeling, this writer is soon generalizing far beyond experimental limits.

\section{Feelings-Experimental Studies}

An experimental study directed to the fundamental issue of the validity of feeling as a unique, non-sensory element as Titchener contends, was reported by Yokoyama (28) who employed the method of paired comparisons. The introspections of this writer's subjects indicate that pleasantness and unpleasantness are meanings or attitudes for which organic sensory content is the sine qua non, at least under the conditions of the paired comparison procedure. 
In Young's investigation of feelings aroused by odors, tastes, etc. (29), unpleasantness was found to be associated with reactions away from the stimulus-object, whereas pleasantness was organically-kinæsthetically negative,-the subject did nothing. Corwin (5) believes that these results were due to the conditions of the experiment which made pursuit unnecessary under pleasantness. With certain changes in the setting, Corwin found that pleasantness correlated with actual pursuit, tendencies to pursuit, or a kind of expansion or relaxation toward the stimulus-object.

Color and form appear to act in independence in determining the affective response to a combined color-form, according to Yokoyama (28). The affective tendency of the color-form unit varies approximately with the algebraic sum of the affective tendencies of the constituent color and form. This finding is essentially in accord with the orthodox conception of the simplicity of feeling tones, as, for example, that given by Geissler in the Titchener Commemorative volume: "the greater the pleasantness of the individual constituents, the greater will be the pleasantness of the combination." M. F. Washburn (24), using the method of judgments of single stimuli, reaches a different conclusion, that the effect of the combination is by no means the summation of the effects of the elements. Frequently two colors, individually pleasant, form an unpleasant combination. Washburn and Grose (25) found it possible to change the affective value of color by four devices: (I) ordinary adaptation (affective fatigue); (2) shifting of attention to various constituent features; (3) imagining different contexts; and (4) deliberately setting up the contrary reaction (compensation). The method of imaginary context was most frequently and successfully employed by the subjects. Extreme judgments were harder to change than moderate; extreme unpleasantness was harder to change than extreme pleasantness.

The emotional significance of various lines (drawn by pen) was studied by Lundholm (14). For example, beauty is expressed by unity of direction, continuity, roundness of curves, lack of angles and a certain symmetry; ugliness by the reverse of these. Anger, sorrow, etc., are suggested by various combinations of these factors.

An extensive study of the dynamic effects of colors was undertaken by Pressey (19). Performances in tapping, multiplying, reaction-time, etc., were not perceptibly influenced by either color or light intensity. Introspective estimates of feeling attitudes 
varied from subject to subject with agreement that the affective value became less with habituation. Reviewing the literature, Pressey feels that there is no reliable evidence that hues have a marked effect either upon emotional tone or on ability in mental work.

\section{REFERENCES}

1. Boyd, W. A Child's Fears. J. of Exper. Ped., 1919, 5, 128-140.

2. BurTt, H. E. The Inspiration-Expiration Ratio During Truth and Falsehood. J. of Exper. Psychol., 1921, 4, 1-23.

3. BurTt, H. E. Further Technique for Inspiration-Expiration Ratios. J. of Exper. Psychol., I921, 4, I06-III.

4. Buscaino, V. M. Ropporte tra stato subiettivo e manifestazione somatiche netta dottrinadelle emozione. I centri encepalici dei reflessi emotivi. Riv. di Psicol., 1920, 16, I67-177.

5. Corwin, G. H. The Involuntary Response to Pleasantness. Amer. J. of Psychol,, 1921, 32, 563-71.

6. Duprat, G. L. Expansion and Depression. J. de Psychol., 1920, 17, 332-336.

7. Ferrari, G. C. Psicologia dei moribundi. Riv. di Psicol., 1920, 16, 101-107.

8. Gualino, L. Psicofisiologia dei Fucilandi. Riv. di Psicol., 1920, 16, 42-60.

9. Janet, P. The Fear of Action. J. of Abnor. Psychol. \& Soc. Psychol, 1921, 26, $150-16 r$.

10. Kaiser, I. R. The Psychology of the Thrill. Ped. Sem., 1920, 27, 243-280.

I1. Kaytor, J. R. An Attempt toward a Naturalistic Description of Emotions. Psychol. Reo., 1921, 28, 19-43, I20-141.

12. Larguier des Banels, J. Le Frisson Contribution a la Psychologie des Sentiments. J. de Psychol., 1920, 17, 168-172.

I3. Link, H. C. Emotions and Instincts. Amer. J. of Psychol., 1921, 32, 134-I45.

14. Lundrolm, $\mathrm{H}$. The Affective Tone of Lines: Experimental Researches. Psychol. Rev., I921, 28, 43-6I.

15. Marston, W. M. Psychological Possibilities in the Deception Tests. J. of Crim. Law G Criminol., 1921, 1I, 55 I.

16. McDougali, W. Belief as a Derived Emotion. Psychol. Rev., 1921, 28, 315-328.

17. Moore, R. C. The Emotion of Admiration and its Development in Children. J. of Exper. Ped., 1920, 5, 221-236.

18. Presser, S. L. The Influence of Color Upon Mental and Motor Efficiency. Amer. J. of Psychol., 1921, 32, 326-357.

19. Pressey, S. L. A Group Scale for Investigating the Emotions. J. of Abnor. Psychol. \& Soc. Psychol., 1921, 26, 55-65.

20. Rucksтсн, C. A. A Preliminary Study of the Emotions. Psychol. Reo. Monograph, 1921, No. 136, 29-50.

21. Russell, F. T. A Poet's Portrayal of Emotions. Psychol. Rev., I921, 28, 222-238.

22. Shand, A. F. Of Impulse, Emotion and Instinct. Proc. Atist. Soc., 1920, 20, 79-88.

23. Tilaey, F. \& Rilex, H. A. The Form and Function of the Central Neroous Systems. New York: Hoeber, 1921. Pp. xxiv + 1020 .

24. Washburn, M. F. The Relation of the Pleasantness of Color Combinations to that of the Color Seen Singly. Amer. J. of Psychol., 1921, 32, 145-147. 
25. Washburn, M. F. \& Grose, S. L. Voluntary Control of Likes and Dislikes; The Effect of An Attempt Voluntarily to Change the Affective Value of Colors. Amer. J. of Psychol., 1921, 32, 284-290.

26. Woodwortr, R. S. Psychology: $A$ Study of Mental Life. New York: Holt, 1921. Pp. $x+580$.

27. Yokoyaua, M. Affective Tendency as Conditioned by Color and Form. Amer. $J$. of Psychol., I921, 32, 8I-108.

28. Yoxoyama, M. The Nature of the Affective Judgment in the Method of Paired Comparison. Amer. J. of Psychol., 1921, 32, 357-370.

29. Young, P. T. Pleasantness and Unpleasantness in Relation to Organic Response. Amer. J. of Psychol., 1921, 32, 38-54. 